\title{
Endoscopic transnasal anterior release and posterior reduction without odontoidectomy for irreducible atlantoaxial dislocation
}

\author{
Xiangsheng Tang ${ }^{1 \dagger}$, Xinjie $\mathrm{Wu}^{1,2 \dagger}$, Mingsheng Tan ${ }^{1,2^{*}}$, Ping Yi ${ }^{1}$, Feng Yang ${ }^{1}$ and Qingying Hao ${ }^{1}$
}

\begin{abstract}
Background: To investigate the efficacy and safety of endoscopic transnasal anterior release and posterior reduction without odontoidectomy to treat irreducible atlantoaxial dislocation (IAAD).

Methods: A series of 9 patients with IAAD underwent endoscopic transnasal anterior release and posterior reduction without odontoidectomy. Etiology, instrumentation, fusion rate, and complications were documented. All patients were assessed clinically and radiologically for neurological recovery using the Japanese Orthopedic Association (JOA) score, atlantodontoid interval (ADI), and cervicomedullary angle (CMA).

Results: The mean age of the patients was 41.6 years, ranging from 14 to 60 years. Pathology showed os odontoideum in 3 patients, old traumatic dens fracture in 3 patients, occipitalization of $\mathrm{C} 1$ in 2 patients, and rheumatoid arthritis in 1 patient. Seven patients underwent C1-C2 pedicle screw fixations, and 2 patients required occipitocervical fixation. Eight cases resulted in complete reduction and 1 in partial reduction. Complications included one superficial infection related to the posterior approach. All patients were followed up for an average of 17 (range 13-32) months. Bony fusion was confirmed in all cases under radiologic assessment at 1 year postoperatively, and the bony fusion rate reached 100\%. Moreover, no instrumental failure occurred during the entire follow-up period. The JOA score improved from $7.21 \pm 1.62$ to $12.28 \pm 0.81$ at the last follow-up. The ADI of 9 cases was $7.06 \pm 0.85 \mathrm{~mm}$ preoperatively, which decreased to $2.26 \pm 0.56 \mathrm{~mm}$ at the final follow-up. CMA improved from $103.80^{\circ} \pm 4.16^{\circ}$ to $143.23^{\circ} \pm 7.47^{\circ}$ postoperatively.

Conclusion: With transnasal approach and lack of odontoidectomy, this method could not only treat IAAD safely and effectively, but also reduce the possibility of many complications associated with the traditional transoral approach and odontoidectomy.
\end{abstract}

Keywords: Atlantoaxial, Reduction, Anterior release, Endoscopy, Transnasal

\section{Background}

The atlantoaxial joint is a complex region of the spine with unique anatomical and functional relationships [1]. Trauma, inflammation, and congenital anomalies of the odontoid can destroy the odontoid or the transverse ligament of the atlas, resulting in atlantoaxial instability. If

\footnotetext{
* Correspondence: doctortan_123@126.com

${ }^{+}$Xiangsheng Tang and Xinjie Wu contributed equally to this study and should be considered co-first authors.

'Department of Spinal Surgery, China-Japan Friendship Hospital, Beijing 100029, People's Republic of China

${ }^{2}$ Graduate School of Peking Union Medical College, Beijing 100730, People's Republic of China
}

(c) The Author(s). 2019 Open Access This article is distributed under the terms of the Creative Commons Attribution 4.0 International License (http://creativecommons.org/licenses/by/4.0/), which permits unrestricted use, distribution, and reproduction in any medium, provided you give appropriate credit to the original author(s) and the source, provide a link to the Creative Commons license, and indicate if changes were made. The Creative Commons Public Domain Dedication waiver (http://creativecommons.org/publicdomain/zero/1.0/) applies to the data made available in this article, unless otherwise stated.

timely treatment is not provided and the instability can be reduced by skull traction or only by posterior surgery, this condition is referred to reducible atlantoaxial dislocation (AAD), otherwise to irreducible atlantoaxial dislocation (IAAD). IAAD remains an ongoing challenge for spinal surgeons. Traditionally, transoral or transnasal odontoidectomy has been used to treat IAAD. However, these techniques carry a high risk of cerebrospinal fluid (CSF) leakage and wound infection [2]. In addition, pure odontoidectomy without posterior fixation cannot correct the swan-neck deformity and accelerates degeneration of the subaxial cervical spine [3]. Compared with the standard 
Endoscopic transnasal odontoidectomy, we explored alternative strategies for treating IAAD, developing a novel technique involving endoscopic transnasal anterior release and posterior reduction without odontoidectomy.

\section{Materials and methods}

\section{Patients}

Between September 2014 and June 2016, 9 patients (7 males, 2 females) with IAAD who underwent surgery were retrospectively analyzed. The following selection criteria were applied: patients with IAAD that could not be reduced by 2 weeks of skull traction and no bony fusion in the $\mathrm{C} 1-\mathrm{C} 2$ facet joints on plain radiograph and $\mathrm{CT}$ scan. Exclusion criteria were as follows: patients with IAAD that could be reduced by skull traction, bony fusion in the $\mathrm{C} 1-$ C2 facet joints on plain radiograph and CT scan, and intolerance to surgery and severe heart, lung, liver, or kidney diseases. The mean age of the patients was 41.6 years, ranging from 14 to 60 years. In this study, all cases presented with occipitocervical pain, limited cervical motion, extremity numbness, weakness, and gait disturbance. The indications for surgery were neurological deficits and/or severe spinal cord compression. All patients underwent endoscopic transnasal anterior release with posterior reduction and instrumented fusion. The clinical data details of all patients are shown in Table 1.

\section{Preoperative preparation}

Radiological evaluations included X-ray plain film, computed tomography and 3D reconstruction (CT), and magnetic resonance imaging (MRI) (Fig. 1). The reducibility of all cases was identified by attempted skull traction under general anesthesia using fluoroscopy. The initial weight is 5 $\mathrm{kg}$. After $3 \mathrm{~min}$ of traction, according to the result under the fluoroscopy, we gradually increase the weight $(1-2 \mathrm{~kg} / \mathrm{time})$, and the maximum weight is $1 / 6$ of the patient's weight $(10 \sim 13 \mathrm{~kg})$. No "reducible" cases were observed in our study. Neurological function was monitored by intraoperative somatosensory-evoked potentials. After fiberoptic oral

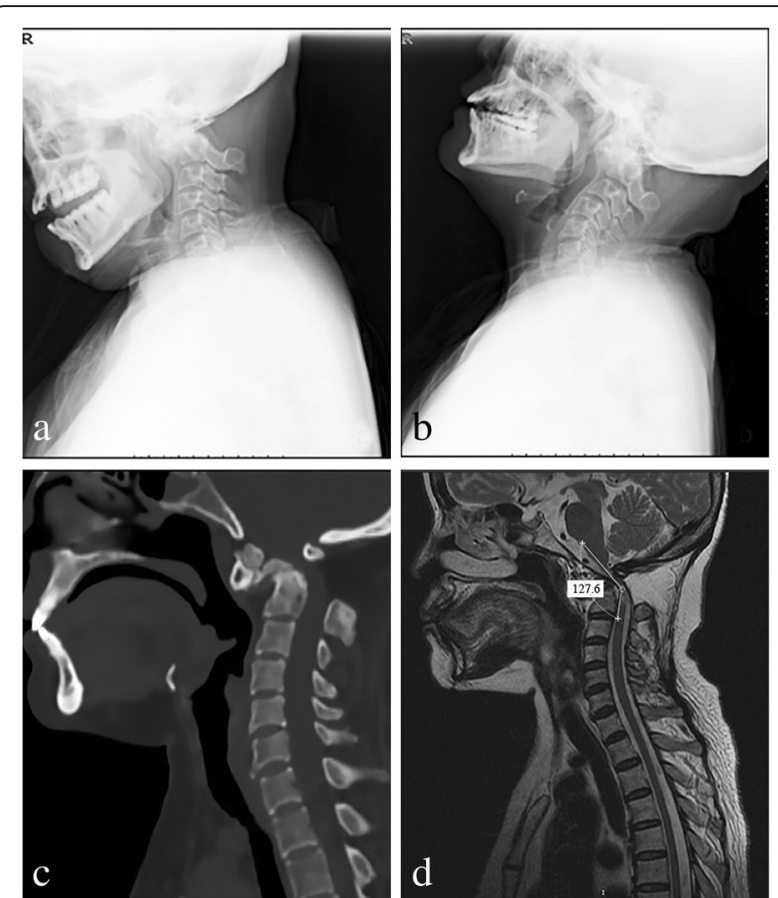

Fig. 1 Case 6, 57-year-old female diagnosed with os odontoideum. $\mathbf{a}, \mathbf{b}$ Flexion-extension radiographs showed no dynamic change of atlantodental interval (ADI) from flexion to extension. c Preoperative sagittal CT showing that the ADI is enlarged and the space available for the spinal cord $(S A C)$ is decreased. d Sagittal MRI showed ventral compression of the spinal cord and a reduced CMA of $127.60^{\circ}$.

intubation and administration of general anesthesia, the patient was placed in the supine position with their head immobilized with a Mayfield head holder. The operating table was tilted $15^{\circ}$ to the right to facilitate the right-handed surgeon. The patient's nose and nares were prepared with $7.5 \%$ povidone iodine solution, followed by placement of oxymetazoline-soaked pledgets into the nasal cavity to promote vasoconstriction and decongestion of the nasal mucosa. All procedures were performed by the same senior orthopedic surgeon and the same otolaryngologist.

Table 1 Clinical characteristics, applied surgeries, and outcomes

\begin{tabular}{|c|c|c|c|c|c|c|}
\hline Case & Gender & Age (years) & Diagnosis & Surgical protocol & Reduction on radiography & Complication \\
\hline 1 & M & 39 & Os odontoideum & ETAR+PRIF(C1-C2) & Complete & No \\
\hline 2 & $\mathrm{~F}$ & 14 & Os odontoideum & $\mathrm{ETAR+PRIF(C1-C2)}$ & Complete & No \\
\hline 3 & M & 53 & Old traumatic dens fracture & ETAR+PRIF(C1-C2) & Complete & No \\
\hline 4 & M & 31 & Occipitalization & ETAR+PRIF(CO-C2) & Complete & No \\
\hline 5 & M & 60 & Old traumatic dens fracture & ETAR+PRIF(C1-C2) & Complete & Superficial wound infection \\
\hline 6 & $\mathrm{~F}$ & 57 & Os odontoideum & ETAR+PRIF(C1-C2) & Partial & No \\
\hline 7 & M & 40 & Occipitalization & ETAR+PRIF(CO-C2) & Complete & No \\
\hline 8 & M & 45 & Rheumatoid arthritis & ETAR+PRIF(C1-C2) & Complete & No \\
\hline 9 & M & 35 & Old traumatic dens fracture & ETAR+PRIF(C1-C2) & Complete & No \\
\hline
\end{tabular}

$M$ male, $F$ female, ETAR endoscopic transnasal anterior release, PRIF posterior reduction and instrumented fusion 


\section{Surgical procedure}

\section{Endoscopic transnasal anterior release}

The procedure utilized rigid-rod endoscopes that were 4 $\mathrm{mm}$ in diameter and $18 \mathrm{~cm}$ in length with lens angles of $0^{\circ}$ and $30^{\circ}$ mounted to a digital video camera system (Karl Storz GmbH \& Co. Tuttlingen, Germany). All procedures were performed using two-nostril endoscopic techniques (Fig. 2). The bilateral middle turbinates, inferior turbinates, and the sphenoid sinus anterior wall were not resected. The bilateral inferior turbinates were lateralized, and the posterior $1 \mathrm{~cm}$ of the nasal septum was removed to enlarge the choana for wider exposure and to facilitate the bilateral application of instrumentations, which avoided continuously pushing the septum into the endoscope and compromising visualization. After identifying the anterior $\mathrm{C} 1$ tubercle via anatomical landmarks and fluoroscopy, a small linear incision was made in the midline of the nasopharyngeal mucosa. The approach is straight to the midline of the nasopharynx rather than making a U-shaped flap, decreasing the risk of damage to the adjacent structures, facilitating the wound healing process, and providing a sufficient working space. Then, the bilateral longus coli, longus capitis, and anterior longitudinal ligament were dissected caudal to the anterior ring of $\mathrm{C} 1$. We further dissected subperiosteally as far as the lateral margins of the $\mathrm{C} 1-\mathrm{C} 2$ lateral masses with high-speed drills. The anterior joint capsules, the cartilage of the bilateral C1-2 lateral joints, and any scar tissue or hyperplastic osteotylus were excised. Notably, this technique preserves the anterior arch of the atlas, and if necessary, it only involves drilling into the anterior-inferior portion around the midline while maintaining the continuity of the $\mathrm{C} 1$ ring. Successful release was achieved when the joint space between the lateral masses of the atlas and axis was elevated to $3-5 \mathrm{~mm}$ [4]. When the $\mathrm{C} 1$ lateral mass was levered up $3-5 \mathrm{~mm}$, the $\mathrm{C} 1 / 2$ has adequate flexibility matching the aforementioned criterion, complete reduction can be achieved in most cases, and there is no need to dissect the odontoid process. Repeated elevation with resection of tissues in front of the $\mathrm{C} 1$ lateral mass and around the $\mathrm{C} 1$ anterior arch was performed until the joint space fulfilled the aforementioned criteria. After irrigation, the incision was closed. Finally, both nasal cavities were packed with expansion sponges. Note that extreme care should be taken when turning the patient to the prone position. All patients had a Philadelphia collar support to prevent atlantoaxial displacement while being turned prone. Therefore, spinal cord injury secondary to atlantoaxial instability during the transition was minimized.

\section{Posterior reduction and instrumented fusion}

Two different techniques were used based on the state of dislocation and bone abnormalities (Fig. 3). Occipitocervical fusion (OCF) is recommended for patients with deformities of the $\mathrm{C} 1$ posterior arch or lateral masses which impeded instrumentation. According to the previous study [5], we used Mimics v17.0 (Materialise, Leuven, Belgium) and 3-matic v9.0 (Materialise) to
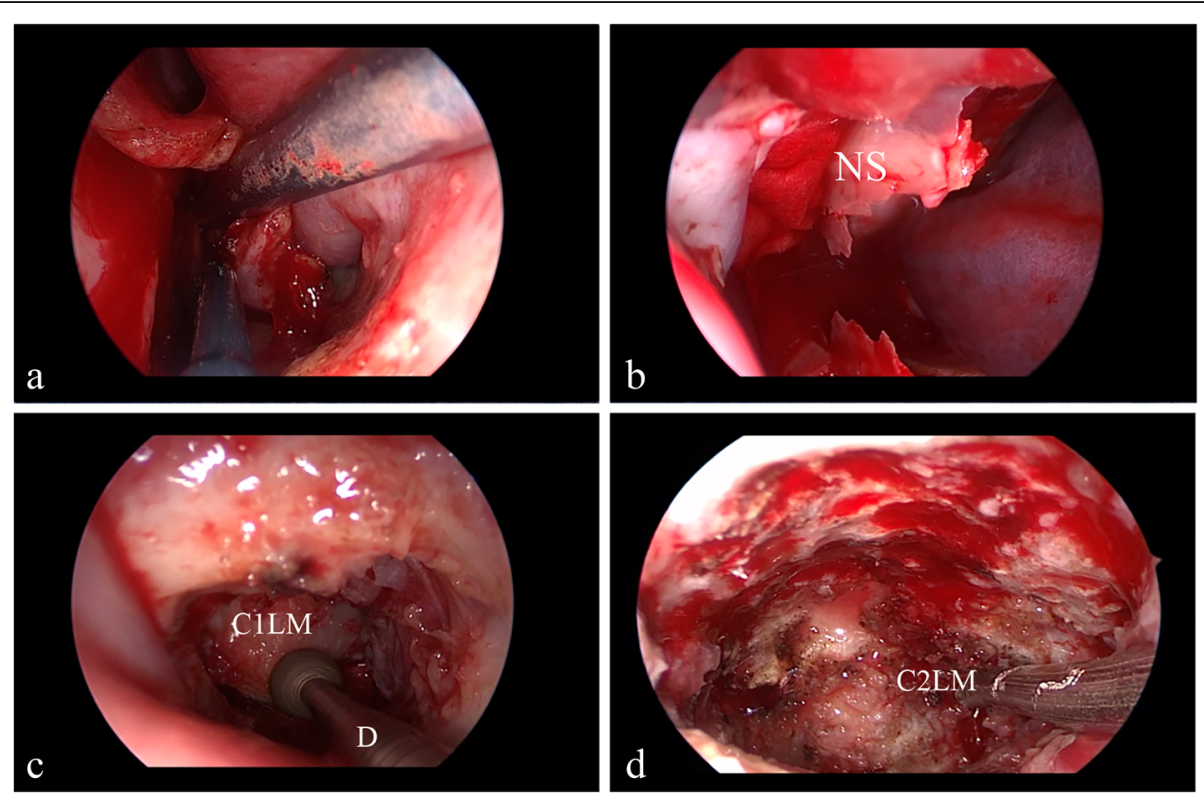

Fig. 2 Illustration of anterior transnasal release. a The choana was entered and the mucosa of the rhinopharynx was dissected. b The posterior nasal septum was removed. c Expose the lateral masses of the atlas with high-speed drills. $\mathbf{d}$ Expose the lateral masses of the axis. Note: NS, nasal septum; D, drill; C1LM, lateral masses of the atlas; C2LM, lateral masses of the axis 

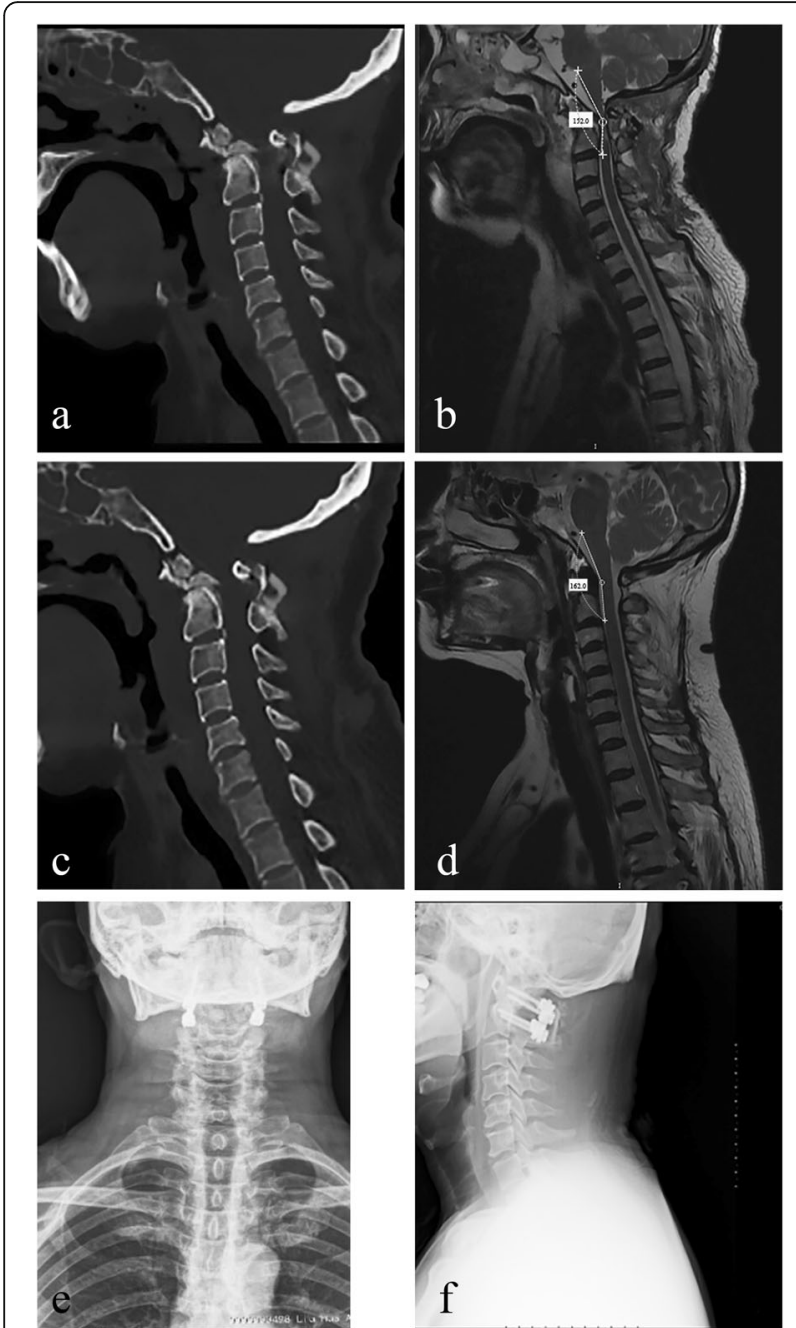

Fig. 3 a Sagittal CT showed reduction and restoration 1 month after operation. b MRI sagittal T2-weighted films 1 month after operation showed ventral medullary decompression with CMA recovery to approximately $152.00^{\circ}$. c At 13 months follow-up, sagittal CT showed no instrument loosening, no loss of reduction, and evidence of bony fusion. d At 13 months follow-up, MRI sagittal T2-weighted image showed CMA recovery to approximately $162.00^{\circ}$. e, $\mathbf{f}$ Postoperative X-ray showed good internal fixation

confirm whether $\mathrm{C} 1-\mathrm{C} 2$ pedicle screws can be fixed. During placement of the $\mathrm{C} 1$ pedicle screws [6], the $\mathrm{C} 1$ posterior arch was dissected approximately $18-20 \mathrm{~mm}$ (14-15 $\mathrm{mm}$ in children) lateral to the posterior tubercle along the posterior-inferior border subperiosteally using two Penfield dissectors. The $\mathrm{C} 2$ nerve root and venous plexus were dissected caudally, whereas the vertebral artery (VA) was dissected rostrally. If the height of the $\mathrm{C} 1$ posterior arch at the VA groove was less than $4 \mathrm{~mm}$, then the "pedicle exposure technique" (PET) was performed, which we discussed in a previous study [7]. A high-speed burr was used to remove the approximately 3-mm-long outer narrow bone of the $\mathrm{C} 1$ posterior arch at the VA groove along the trajectory, and a $3.5-\mathrm{mm}$ screw could then be inserted safely. The optimal trajectory was planned using preoperative CT scans, approximately 5 to $10^{\circ}$ in the cephalad direction and 10 to $15^{\circ}$ in the medial direction. In some situations, a $6 \times 8 \mathrm{~mm}$ autologous fascia was placed between the end of the screw and the VA to protect the VA. Axial pedicle screws were inserted and connected to the $\mathrm{C} 1$ screws tightly with a pre-curved rod bilaterally. This technique allowed further reduction as the locking caps were tightened to the rod. As shown by the C-arm, the internal fixation was well placed and the atlantoaxial joint was sufficiently reduced (Fig. 3). After irrigation, autologous bone grafting was performed. Ultimately, the incision was closed in layers, and a drainage tube was placed inside the surgical site.

\section{Postoperative management and follow-up}

All patients were extubated after recovery from anesthesia and were allowed oral food intake on the next day postoperatively. The drainage tube was removed within $48 \mathrm{~h}$ postoperatively. The expansion sponges packed into the nasal cavities were removed on the third day postoperatively. Furthermore, all patients were required to wear a rigid cervical collar for approximately 6-8 weeks after surgery. The atlantodontoid interval (ADI) was defined as the distance from posterior edge of anterior arch to anterior edge of odontoid. The cervicomedullary angle (CMA) was defined by the angle between the two lines on the ventral side of the medulla oblongata and upper cervical spinal cord. The ADI was recorded at CT images 1 month, 1 year, and then annually after operation. Bony fusion was assessed at CT images 1 month and 1 year after operation, and this was confirmed on CT when bridging trabeculae were seen [8]. The CMA was recorded under MRI sagittal T2-weighted films 1 month after operation and the final follow-up. Complete reduction was identified as ADI $\leq 3 \mathrm{~mm}$ in adults and $\leq 5 \mathrm{~mm}$ in children, whereas partial reduction was defined as ADI of less than or equal to $5 \mathrm{~mm}$ but more than $3 \mathrm{~mm}$ in adults and 5 to $7 \mathrm{~mm}$ in children [4]. The Japanese Orthopedic Association (JOA) score was used to assess improvement in neurological function, and The JOA scores at 1-month and the last follow-up visit were compared with preoperative JOA scores. Redislocation and complications such as neurovascular injury, infection, or CSF leakage were recorded during the follow-up period.

\section{Statistical analysis}

The paired $t$ test was used to compare changes before and after surgery with parametric values. The $t$ test was considered significant if the $P$ value was less than 0.05. Statistical analyses were performed using SPSS 20.0 software. 


\section{Results}

The mean duration of the operation was $220 \mathrm{~min}$ (range 180-290 min), and intraoperative blood loss ranged from 240 to $810 \mathrm{ml}$ (mean $390 \mathrm{ml}$ ). All patients were extubated after recovery from anesthesia and were allowed oral food intake on the next postoperative day. No patients required tracheostomy or reintubation. In addition, no significant complications occurred during surgery, including VA or spinal cord injuries or CSF leakage. All wounds healed without infection, except for one patient with a superficial infection related to the posterior approach, which was noted 1.5 months later and was treated successfully with intermittent debridement and antibiotics.

All patients were followed up for an average of 17 (range 13-32) months. During the follow-up, bony fusion was confirmed in all cases under radiologic assessment, 1 year after operation, and the bony fusion rate reached $100 \%$. Eight of nine patients had complete reduction, and one had incomplete reduction based on CT scan and MRI findings at the final follow up. Moreover, no instrumental failures occurred during the entire follow-up period. All patients showed significant improvements neurologically and radiologically at the final follow-up compared with preoperative parameters (Table 2). In addition, at the final follow-up, the pediatric patient in our study experienced complete resolution of neck pain and achieved stability in various directions without the "crankshaft phenomenon" [9].

\section{Discussion}

In 1968, Greenberg first divided AAD into 2 subcategories, reducible and irreducible, and further devised a treatment strategy based on this factor as well as the etiology of the dislocation [10]. Although chronic AAD derives from various etiologies, anterior dislocation of the atlas is the most common directional endpoint. Due to progressive anterior translation, the atlas eventually loses its support from the superior $\mathrm{C} 2$ facets and migrates further anteriorly. The $\mathrm{C} 1-\mathrm{C} 2$ facets gradually reshape and the articular surface becomes increasingly vertically sloped. Then, capsules of the atlantoaxial joint, muscles, and ligaments become shortened and eventually contracted, leading to IAAD.
The most important issue to consider is whether the AAD is reducible. If preoperative dynamic X-ray confirms its reducibility, then surgical reduction and occipitocervical or atlantoaxial fusion are adequate. In our study, reducibility was investigated further under general anesthesia, and only true IAAD patients underwent anterior release and posterior reduction. Due to the presence of neck pain, muscle tension, and positional restrictions, the reducibility of AAD could not be reliably assessed with dynamic X-rays.

Currently, there is no consensus as to the ideal surgical treatment for IAAD. Historically, surgical treatment of IAAD has been performed using a pure posterior approach. One disadvantage of this technique is the need to flex the head during the operation to achieve adequate exposure of the $\mathrm{C} 1-\mathrm{C} 2$, increasing the risk of fatal injury to the spinal cord. Furthermore, the posterior approach may be contraindicated in cases in which the dislocated posterior arch severely compresses the spinal cord [11]. Additionally, single posterior approaches often result in incomplete reduction.

For the past several decades, the transoral approachwith or without the addition of variations such as the transmandibular-circumglossal approach or Le Fort osteotomies-has been utilized to treat symptomatic IAAD, including odontoidectomy [12, 13]. This approach provides the most direct route to the ventral craniocervical junction. However, this technique does have disadvantages. (1) The transoral approach requires opening the mouth (at least $2.5 \mathrm{~cm}$ ) and retracting the tongue and soft palate, which can cause dental injury, edema, or necrosis of the tongue and upper airway obstruction due to edema. Therefore, the transoral approach is contraindicated in patients with micrognathia [14, 15]. In addition, palatal division can increase the risk of hypernasal speech and nasal regurgitation from velopharyngeal insufficiency (VPI). (2) Patients may need prolonged postoperative intubation or tracheostomy due to airway swelling and upper airway obstruction. Landeiro et al. reported that the rate of postoperative tracheostomy was as high as $26.3 \%$ in transoral odontoidectomy [16]. (3) The pharyngeal incision is constantly exposed to oral flora and saliva, which increases the risk of infection and the need for nasogastric tube feeding [17]. (4) The surgical area is deep and the surgical corridor is narrow under an operative

Table 2 Neurological and radiological outcomes

\begin{tabular}{lllll}
\hline Parameters & Preoperative & One month after operation & One year after operation & Final follow-up \\
\hline JOA $(n=9)$ & $7.21 \pm 1.62$ & $10.11 \pm 1.27^{* *}$ & $12.11 \pm 0.78^{* *}$ & $12.28 \pm 0.81^{* *}$ \\
ADI $(n=9)$ & $7.06 \pm 0.85$ & $2.16 \pm 0.43^{* *}$ & $2.16 \pm 0.68^{* *}$ & $2.26 \pm 0.56^{* *}$ \\
CMA $(n=9)$ & $103.80 \pm 4.16$ & $137.95 \pm 6.15^{* *}$ & N/A & $143.23 \pm 7.47^{* *}$ \\
& & $P=0.00$ & $P=0.00$ & $P=0.00$ \\
\hline
\end{tabular}

${ }^{* *} P<0.01$, compared with the preoperative group 
microscope. Although transmandibular extension and Le Fort osteotomy can provide increased exposure, there are associated complications, including lingual nerve injury, malocclusion, mandibular pseudarthrosis, cosmetically unacceptable scarring of the lip, and the need for nasogastric tube feeding $[18,19]$. Such drawbacks can increase morbidity and prolong hospitalization, prompting the search for a more minimally invasive method.

Kassamet et al. were the first to describe the successful clinical application of transnasal endoscopic odontoidectomy in a 73-year-old woman with rheumatoid arthritis and cervicomedullary compression [14]. Because the incision is made above the oropharynx and the oral cavity can be avoided without a transoral retractor or splitting of the soft palate, the endoscopic endonasal approach avoids the risk of tongue swelling and tooth damage and can improve visualization, mitigate prolonged intubation, reduce the need for enteral tube feeding, and decrease the risk of affecting phonation. Furthermore, because the wound is not constantly bathed in saliva, the risk of infection is reduced [20,21]. Liu et al. reported that the endoscopic endonasal approach can accelerate recovery and shorten hospital stays [22]. In addition, previous studies suggested that the transnasal approach enables earlier extubation [20, 23]. In our study, extubation after recovery from anesthesia was achieved in all patients, and no tracheostomy or reintubation was needed. Moreover, patients could resume oral feeding on postoperative day 1 . In a recent report of endoscopic endonasal odontoidectomy by Goldschlager et al., extubation was possible shortly after surgery, and oral feeding was resumed on postoperative day 1 on average [22]. In pediatric patients, transoral access to the craniovertebral junction is an arduous task due to the smaller mouth openings of children. Therefore, the transnasal route is an ideal alternative. Tan et al. successfully performed procedures in a patient as young as 3 years old [23]. In our study, the transnasal approach was also feasible in case 2 , which was a 14-year-old child.

Intraoperative and postoperative CSF leaks were reported at relatively higher rates for transnasal endoscopic procedures $(30.0 \%$ and $5.2 \%)$ than for the transoral approach $(0.3 \%$ and $0.8 \%)$ [24]. CSF leaks can be caused by severe compression that causes the dura and ligaments to become very thin, improper manipulation of the last piece of the bony element of the odontoid when it is free-floating, or sharp dissection of the odontoid. Resection of the odontoid process destroys the atlantoaxial joint and the craniovertebral junction (CVJ), which inevitably affects the stability of the atlantoaxial joint. In addition, the small and deep working space makes reconstruction with bone grafts or dural tear repair with sutures difficult, predisposing the patient to a persistent CSF fistula or recurrent meningitis [17].
Spinal cord compression mainly arose from the posterior margin of a fractured $\mathrm{C} 2$ body and odontoid fragment and the posterior arch of the $\mathrm{C} 1$. The anterior tubercle of $\mathrm{C} 1$ and the fractured $\mathrm{C} 2$ body and odontoid fragment were not major factors affecting compression, so resection of the anterior tubercle and the odontoid process was not necessary [25].

After anterior release, posterior reduction as well as internal segmental fixation and fusion were often required to stabilize the atlantoaxial joint. Since subluxation can occur if patients awaited the second stage of posterior fixation and fusion, we recommend the posterior procedure at stage 1 . After the posterior procedures, the atlantoaxial joints achieved reduction and fusion. Reduction is achieved sequentially by the pull strength of instruments via the posterior approach. Another advantage of the posterior approach is the realignment of the atlantoaxial joint, which can prevent subaxial degeneration due to misalignment of the cervical spine [26, 27]. In our study, only 1 patient achieved partial reduction, but this did not result in neurological deficits. Partial reduction can be caused by the lack of intra-spinal canal manipulation with the posterior approach; therefore, soft tissue and scar tissue may remain within the spinal canal and impede the reduction of $\mathrm{C} 1$ to its proper anatomical position. In terms of the instruments for posterior fixation, we recommend $\mathrm{C} 1-\mathrm{C} 2$ pedicle screws because they provide more pullout strength, less irritation of the $\mathrm{C} 2$ nerve root and venous plexus, and a more visible entry point $[28,29]$. For pediatric patients, many studies have verified the feasibility of placing $\mathrm{C} 1$ pedicle screws, even if the height of the $\mathrm{C} 1$ posterior arch is $<4 \mathrm{~mm}[7,30]$. In our study, all patients achieved bony fusion, as determined by radiography, and no implant failures or migrations were observed radiographically at the last follow-up.

The limitations of the study are as follows: low number of subjects, narrow operative field, steep learning curve, and limit in the caudal direction to the inferior base of $\mathrm{C} 2$.

\section{Conclusion}

With transnasal approach and lack of odontoidectomy, this method could not only treat IAAD safely and effectively, but also reduce the possibility of many complications associated with the traditional transoral approach and odontoidectomy.

\footnotetext{
Abbreviations

IAAD: Irreducible atlantoaxial dislocation; CSF: Cerebrospinal fluid;

$C T$ : Computed tomography; MRI: Magnetic resonance imaging;

OCF: Occipitocervical fusion; VA: Vertebral artery; PET: Pedicle exposure

technique; ADI: Atlantodontoid interval; CMA: Cervicomedullary angle;

JOA: Japanese Orthopedic Association
}

Acknowledgements

Not applicable. 


\section{Funding}

This work was supported by grants from Capital Characteristic Clinical project of Beijing Municipal Science \& Technology Commission (http://www. bjkw.gov.cn/n8785584/index.html) (Grant No. Z161100000516009). No individuals employed or contracted by the funders played any role in study design, data collection and analysis, decision to publish, or preparation of the manuscript.

\section{Availability of data and materials}

Data can be made available upon request to the corresponding author

\section{Authors' contributions}

XT and XW participated in concept development, data generation, quality control of the data, data analysis and interpretation, and writing of the manuscript. PY and FY were responsible for the data analysis and participated in the interpretation and presentation of the data. FY provided input into the data interpretation. MT and $\mathrm{QH}$ were involved in the concept development, quality control of the data, and data analysis and interpretation of the manuscript. All authors have read and approved the final version of the submitted manuscript.

\section{Ethics approval and consent to participate}

Ethical approval for this study was obtained from the Medical Ethics Committee of China-Japan Friendship Hospital.

\section{Consent for publication}

Written informed consent was obtained from all participants.

\section{Competing interests}

The authors declare that they have no competing interests.

\section{Publisher's Note}

Springer Nature remains neutral with regard to jurisdictional claims in published maps and institutional affiliations.

\section{Received: 30 December 2018 Accepted: 26 April 2019}

\section{Published online: 06 May 2019}

\section{References}

1. Dickman CA, Locantro J, Fessler RG. The influence of transoral odontoid resection on stability of the craniovertebral junction. J Neurosurg. 1992;77: 525-30 Available from: http://www.ncbi.nlm.nih.gov/pubmed/1527609.

2. Jain VK, Behari S, Banerii D, Bhargava V, Chhabra DK. Transoral decompression for craniovertebral osseous anomalies: perioperative management dilemmas. Neurol India. 1999:47:188-95 Available from: http:// www.ncbi.nlm.nih.gov/pubmed/10514577.

3. Wang S, Yan M, Passias PG, Wang C. Atlantoaxial rotatory fixed dislocation. Spine (Phila. Pa. 1976). 2016;41:E725-32

4. Ma H, Dong L, Liu C, Yi P, Yang F, Tang X, et al. Modified technique of transoral release in one-stage anterior release and posterior reduction for irreducible atlantoaxial dislocation. J Orthop Sci. 2016;21:7-12 Available from: https://doi.org/10.1016/j.jos.2015.10.012.

5. Jiang L, Dong L, Tan M, Yang F, Yi P, Tang X. Accuracy assessment of atlantoaxial pedicle screws assisted by a novel drill guide template. Arch. Orthop. Trauma Surg. Springer. Berlin Heidelberg. 2016;136: 1483-90.

6. Yang F, Dong L, Tan M, Ma H, Yi P, Tang X. In vivo analysis of cervical range of motion after revised $\mathrm{C} 1-\mathrm{C} 2$ pedicle screw technique for pediatric atlantoaxial instability. Pediatr Neurosurg. 2014;49:282-6.

7. Yi $\mathrm{P}$, Dong $\mathrm{L}$, Tan $\mathrm{M}$, Wang $\mathrm{W}$, Tang $\mathrm{X}$, Yang $\mathrm{F}$, et al. Clinical application of a revised screw technique via the $\mathrm{C} 1$ posterior arch and lateral mass in the pediatric population. Pediatr Neurosurg. 2014:49:159-65.

8. Buchowski JM, Liu G, Bunmaprasert T, Rose PS, Riew KD. Anterior cervical fusion assessment: surgical exploration versus radiographic evaluation. Spine (Phila. Pa. 1976). 2008:33:1185-91 Available from: http://www.ncbi.nlm.nih. gov/pubmed/18469691.

9. Rodgers WB, Coran DL, Kharrazi FD, Hall JE, Emans JB. Increasing lordosis of the occipitocervical junction after arthrodesis in young children: the occipitocervical crankshaft phenomenon. J Pediatr Orthop. 1997:17:762-5 Available from: http://www.ncbi.nlm.nih.gov/pubmed/9591978.
10. Greenberg AD. Atlanto-axial dislocations. Brain. 1968;91:655-84 Available from: http://www.ncbi.nlm.nih.gov/pubmed/5704829.

11. Hao D, He B, Zheng $Y$, Zhang Z. Single-stage anterior release and sequential posterior fusion for irreducible atlantoaxial dislocation. Clin Spine Surg. 2016;29:E240-5 Available from: http://www.ncbi.nlm.nih.gov/ pubmed/22874473.

12. Blazier CJ, Hadley MN, Spetzler RF. The transoral surgical approach to craniovertebral pathology. J Neurosci Nurs. 1986;18:57-62 Available from: http://www.ncbi.nlm.nih.gov/pubmed/2937850.

13. Crockard HA. The transoral approach to the base of the brain and upper cervical cord. Ann R Coll Surg Engl. 1985;67:321-5 Available from: http:// www.ncbi.nlm.nih.gov/pubmed/3901865.

14. Kassam AB, Snyderman C, Gardner P, Carrau R, Spiro R. The expanded endonasal approach: a fully endoscopic transnasal approach and resection of the odontoid process: technical case report. Neurosurgery. 2005;57:E213 discussion E213. Available from: http://www.ncbi.nlm.nih. gov/pubmed/15987596.

15. Wu J-C, Mummaneni PV, El-Sayed $I H$. Diseases of the odontoid and craniovertebral junction with management by endoscopic approaches. Otolaryngol Clin North Am. 2011;44:1029-42 Available from: http://www. ncbi.nlm.nih.gov/pubmed/21978894.

16. Landeiro JA, Boechat S, Christoph D de H, Gonçalves MB, de Cl, Lapenta $M A$, et al. Transoral approach to the craniovertebral junction. Arq Neuropsiquiatr. 2007;65:1166-71 Available from: http://www.ncbi.nlm.nih. gov/pubmed/18345423.

17. Wu J-C, Huang W-C, Cheng H, Liang M-L, Ho C-Y, Wong T-T, et al. Endoscopic transnasal transclival odontoidectomy: a new approach to decompression: technical case report. Neurosurgery. 2008;63:ONSE92-4 discussion ONSE94. Available from: http://www.ncbi.nlm.nih.gov/ pubmed/18728615.

18. Kanamori Y, Miyamoto K, Hosoe H, Fujitsuka H, Tatematsu N, Shimizu K. Transoral approach using the mandibular osteotomy for atlantoaxial vertical subluxation in juvenile rheumatoid arthritis associated with mandibular micrognathia. J Spinal Disord Tech. 2003;16:221-4 Available from: http:// www.ncbi.nlm.nih.gov/pubmed/12679681.

19. Balasingam V, Anderson GJ, Gross ND, Cheng C-M, Noguchi A, Dogan A, et al. Anatomical analysis of transoral surgical approaches to the clivus. J Neurosurg. 2006;105:301-8 Available from: http://www.ncbi.nIm.nih.gov/ pubmed/17219838.

20. Nayak JV, Gardner PA, Vescan AD, Carrau RL, Kassam AB, Snyderman CH. Experience with the expanded endonasal approach for resection of the odontoid process in rheumatoid disease. Am J Rhinol. 21:601-6 Available from: http://www.ncbi.nlm.nih.gov/pubmed/17999797.

21. Yu Y, Hu F, Zhang $X$, Sun C. Endoscopic transnasal odontoidectomy. Sports Med Arthrosc. 2016;24:2-6 Available from: http://www.ncbi.nlm.nih.gov/ pubmed/26752771.

22. Liu JK, Patel J, Goldstein IM, Eloy JA. Endoscopic endonasal transclival transodontoid approach for ventral decompression of the craniovertebral junction: operative technique and nuances. Neurosurg Focus. 2015;38:E17 Available from: http://www.ncbi.nlm.nih.gov/ pubmed/25828493.

23. Tan SH, Ganesan D, Prepageran N, Waran V. A minimally invasive endoscopic transnasal approach to the craniovertebral junction in the paediatric population. Eur Arch Otorhinolaryngol. 2014;271:3101-5 Available from: http://www.ncbi.nlm.nih.gov/pubmed/24986428.

24. Shriver MF, Kshettry VR, Sindwani R, Woodard T, Benzel EC, Recinos PF. Transoral and transnasal odontoidectomy complications: a systematic review and meta-analysis. Clin Neurol Neurosurg. 2016:148:121-9 Available from: http://www.ncbi.nlm.nih.gov/pubmed/27442001.

25. Pal GP. Sherk HH. The vertical stability of the cervical spine. Spine (Phila. Pa. 1976). 1988;13:447-9 Available from: http://www.ncbi.nlm.nih. gov/pubmed/3187688.

26. Ishii K, Matsumoto M, Takahashi Y, Okada E, Watanabe K, Tsuji T, et al. Risk factors for development of subaxial subluxations following atlantoaxial arthrodesis for atlantoaxial subluxations in rheumatoid arthritis. Spine (Phila. Pa. 1976). 2010:35:1551-5 Available from: http://www.ncbi.nlm.nih.gov/ pubmed/20072093.

27. Yoshida G, Kamiya M, Yukawa $Y$, Kanemura $T$, Imagama S, Matsuyama $Y$, et al. Rheumatoid vertical and subaxial subluxation can be prevented by atlantoaxial posterior screw fixation. Eur Spine J. 2012;21:2498-505 Available from: http://www.ncbi.nlm.nih.gov/pubmed/22825632. 
28. Yeom JS, Kafle D, Nguyen NQ, Noh W, Park K-W, Chang B-S, et al. Routine insertion of the lateral mass screw via the posterior arch for $\mathrm{C} 1$ fixation: feasibility and related complications. Spine J. 2012;12:476-83 Available from: http://www.ncbi.nlm.nih.gov/pubmed/22795381.

29. Thomas JA, Tredway T, Fessler RG, Sandhu FA. An alternate method for placement of C-1 screws. J. Neurosurg Spine. 2010;12:337-41 Available from: http://www.ncbi.nlm.nih.gov/pubmed/20367368.

30. Huang D-G, He S-M, Pan J-W, Hui H, Hu H-M, He B-R, et al. Is the $4 \mathrm{~mm}$ height of the vertebral artery groove really a limitation of $\mathrm{Cl}$ pedicle screw insertion? Eur. Spine J. 2014;23:1109-14 Available from: http://www.ncbi. nlm.nih.gov/pubmed/24509775.

Ready to submit your research? Choose BMC and benefit from:

- fast, convenient online submission

- thorough peer review by experienced researchers in your field

- rapid publication on acceptance

- support for research data, including large and complex data types

- gold Open Access which fosters wider collaboration and increased citations

- maximum visibility for your research: over $100 \mathrm{M}$ website views per year

At BMC, research is always in progress.

Learn more biomedcentral.com/submissions 